\title{
Factors Affecting the Onset of Cercospora Leaf Spot Epidemics in Sugar Beet and Establishment of Disease-Monitoring Thresholds
}

\author{
P. F. J. Wolf and J. A. Verreet
}

Department of Phytopathology, Christian-Albrechts-Universität Kiel, Hermann Rodewald Str. 9, D-24118 Kiel, Germany. Accepted for publication 6 November 2004.

\begin{abstract}
Wolf, P. F. J., and Verreet, J. A. 2005. Factors affecting the onset of Cercospora leaf spot epidemics in sugar beet and establishment of disease-monitoring thresholds. Phytopathology 95:269-274.

Severe Cercospora leaf spots epidemics in sugar beet during the late 1980 s and early 1990s in southern Germany prompted us to initiate investigations on the epidemiology of the causal agent, Cercospora beticola. The data set involved 69 field trials (1993 to 2003) focusing on factors affecting the epidemic onset of this disease. Observations were made at weekly intervals, recording the calendar week when canopy closure occurred (growth stage according to BBCH scale $=39$ ) and symptom development by assessing the percentage of infected leaf area on a single-leaf basis ( $n=40$ plants). These monitoring trials revealed that epidemic onset varied between early July and mid-September. Hence, the target was to identify the reasons for this variation in order to deduct the most suitable approach for predicting epidemic onset. Differences in cultivar resistance explained part of epidemic onset variability, as did different timings of canopy closure, presumably due to associated microclimate changes. Moreover, meteorological variables were considered as potential reasons for variation in epidemic onset. The weather-dependent infection probability was assessed by daily infection values (DIV) in the range from 0 to 1 using hourly weather data. For calculating DIVs, the temperature effect was quantified by the proportions of the latent period (LP)

further established that air relative humidity $(\mathrm{RH})>95 \%$ or leaf wetness was required for infection and subsequent lesion development. Under field conditions, the probability of leaf wetness was $75 \%$ at $\mathrm{RH}>90 \%$. Therefore, DIVs were set to 0 for $\mathrm{RH} \leq 90 \%$ in the absence of precipitation (moisture index I). Alternatively, the effect of moisture was modeled with a sigmoidal function describing the occurrence of leaf wetness in dependence of $\mathrm{RH}$ in the field (moisture index II). Using this approach, DIV values were cumulated (c-DIV) for each of the 69 trials beginning either at fixed starting dates (1 May, 16 May, or 1 June) or the dates of canopy closure. Accumulation of DIV ended at the time of epidemic onset. The two different moisture index definitions had no significant influence on c-DIV; whereas, for starting time of summation of DIV, the date of canopy closure was more suitable. Values of c-DIV ranged from 7 to 19 in highly susceptible cultivars and 12 to 25 in cultivars with lower susceptibility. Given this variation, c-DIV values were insufficient to explain differences in the date of epidemic onset and thus were not considered suitable for making accurate and precise management decisions. However, a negative prognosis assessing the most likely periods of disease absence was possible by determining the minimum c-DIV as a threshold. This threshold was $7 \mathrm{c}$-DIV for highly susceptible cultivars and $12 \mathrm{c}$-DIV for cultivars with low susceptibility. Crop monitoring is recommended as soon as these threshold values are exceeded so that the exact epidemic onset time can be observed.
\end{abstract} relative to the optimum at 20 to $25^{\circ} \mathrm{C}$, established by artificial inoculation of sugar beet plants in growth cabinets. Artificial infection experiments
Additional keywords: Beta vulgaris, economic damage threshold.
Leaf spot, caused by Cercospora beticola (Sacc.), is the most important foliage disease of sugar beet (Beta vulgaris) in temperate climates $(3,6)$. The disease regularly causes yield loss and the extent of damage depends on time of initiation, progress, and severity of the epidemic $(6,7,15,17,23,27,28,30,31)$.

The usual way of limiting losses due to Cercospora leaf spot is to apply fungicides, mostly according to fixed calendar schedules, although high epidemic variation means that this is not justified for every situation. The sugar beet integrated pest management (IPM) model remedies this situation by timing treatments according to epidemiological threshold levels $(21,28,30,32)$. For advisory services and sugar beet growers, this means that monitoring of the actual disease progress in the crop, including diagnosis and assessment of disease, is required. Therefore, prediction of the epidemic onset could be useful in reducing the efforts for scouting and disease observation.

During our epidemiological studies from 1993 to 2003 in different sugar beet-cropping regions in southern Germany, a high variation in epidemic onset times was evident $(28,30)$, which similarly has been found by other authors $(14,16,24)$. It is crucial,

Corresponding author: P. F. J. Wolf; E-mail address: wolfpfj@t-online.de

DOI: 10.1094/PHYTO-95-0269

C) 2005 The American Phytopathological Society therefore, to identify the reasons for this variation. We hypothesized that the epidemic onset of the disease (target variable) is dependent on (i) canopy development (affecting the microclimate), (ii) level of cultivar resistance, (iii) inoculum potential, and (iv) weather conditions.

Canopy development has to be considered an important factor due to subsequent changes of microclimate. In particular, after row closure, leaf wetness duration is prolonged and relative humidity $(\mathrm{RH})$ is higher within the canopy $(11,12,26)$, favoring epidemic progress.

Cultivar resistance also contributes a substantial influence on epidemic onset as well as on progression of disease $(13,15$, $28,30,31$ ). Our own examination of cultivar resistance confirmed that epidemic onset is being delayed by $\approx 2$ to 4 weeks in cultivars with low susceptibility $(28,30,31)$.

Inoculum potential is a major factor affecting Cercospora leaf spot epidemics, especially in the context of cultural practices used in sugar beet production. The fungus is able to persist on infected beet leaf residue as stromata, preferably on the soil surface; whereas, in the soil, survival is reduced to 2 years $(5,9,12,18)$. Therefore, cultural practices such as tillage to turn under leaf debris are of major importance, as is the distance to beet fields of the previous year. Although a crop rotation with a minimum of 2 years with nonhost crops is recommended as a practical standard in sugar beet cropping $(24,25)$, overall cropping practices may 
vary considerably even within the same production region, leading to large field-to-field variations in inoculum potential.

Meteorological factors have a predominant impact on the development of Cercospora leaf spot. Free water or $\mathrm{RH}>95 \%$ is essential for conidial germination and infection by the fungus $(5,11,12,26)$. Disease development is favored by temperatures between 20 and $30^{\circ} \mathrm{C}$, but strongly inhibited by temperatures $<10^{\circ} \mathrm{C}$ $(4,5,12,26)$.

Based on the above knowledge, we wished to explain the variation in onset times of Cercospora leaf spot in a large set of field trials based on site, crop, and year-specific conditions. The ability to explain these variations is crucial for assessing the likelihood of successful disease prediction, either with explicit prediction of epidemic onset time per se or as negative-prognosis with determination of the disease-free period. This evaluation is carried out here based on a retrospective analysis of factors affecting the time of epidemic onset, based on a large data set summarizing detailed studies of epidemic progress of Cercospora leaf spot in the field.

\section{MATERIALS AND METHODS}

Epidemic onset variation in the field. The data set consisted of 69 field experiments conducted from 1993 to 2003 at 11 sites in southern Germany. In regions where these trials were conducted, sugar beet covered $\approx 15$ to $20 \%$ of arable land and was grown in a 3- or 4-year rotation. For sowing of sugar beet seed in the spring (planting density 18 to $20 \mathrm{~cm}$, row distance $50 \mathrm{~cm}$ ), the fields were plowed during the fall. All cropping measures were conducted according to the regional practice of sugar beet growing (25). Sugar beet cultivars of different susceptibility were included in the field experiments in order to assess the influence of host resistance on epidemic onset. For this purpose, cultivars were classified as having either low or high susceptibility (Table 1). There were three field trials each year from 1994 to $1996(n=9)$, which consisted of a direct comparison of low and highly susceptible cultivars. At all other trial sites $(n=60)$, one low or highly susceptible cultivar was grown (25).

In each trial, symptoms were recorded weekly from the beginning of June until October. On the first assessment date, when the crop began to cover the ground (growth stage 31 following the $\mathrm{BBCH}$ growth-stage scale) (10), 40 plants were selected randomly from fungicide-untreated plots and all leaves of these plants were examined for disease symptoms. Diagnosis was supported by identification of hyphal structures with a hand lens in the field. Epidemic onset was defined as the time when $50 \%$ of the sugar beet plants had at least one lesion on one leaf. This stage of disease development is a very early stage and corresponds to an infected leaf area of about $0.01 \%$. Instead of first symptom appearance, this epidemic stage can be determined with high accuracy (25).

TABLE 1. Sugar beet cultivars used in 69 field trials from 1993 to 2003 in southern Germany

\begin{tabular}{lrcc}
\hline Cultivar name & $n$ & Susceptibility $^{\text {a }}$ & Resistance level \\
\hline Ribella & 13 & 4 & High \\
Patricia & 11 & 4 & High \\
Corinna & 16 & 4 & High \\
Tatjana & 3 & 4 & High \\
Cyntia & 2 & 4 & High \\
Achat & 2 & 4 & High \\
Elan & 3 & 5 & Low \\
Steffi & 4 & 5 & Low \\
Meta & 6 & 6 & Low \\
Evita & 3 & 5 & Low \\
Hilma & 3 & 5 & Low \\
Orbis & 3 & 5 & Low
\end{tabular}

a Degree of susceptibility of 1 to 9 where $1=$ lowest and $9=$ highest susceptibility on the scale (1).
Model conception. The Cercospora leaf spot model is based on the calculation of weather-dependent daily infection values (DIV) as described below. Through addition of consecutive DIVs, a cumulative DIV value (c-DIV) was determined for each trial. Calculation of c-DIV started with the first day of the week when canopy closure occurred or, alternatively, on arbitrarily selected dates (1 May, 16 May, or 1 June). By using the time of canopy closure, the starting point was held flexible in order to account for differences in beet crop development $(11,26)$. Canopy closure was defined as the time when leaves of $90 \%$ of beet plants in adjacent rows began to touch or overlap. Calculation of c-DIV stopped with the last day of the week when epidemic onset (defined above) occurred:

$$
\mathrm{cDIV}=\sum_{k=1}^{n} \mathrm{DIV}_{k}
$$

where $\mathrm{c}$-DIV $=$ cumulative daily infection value, $k=k$ th day of record, and $\mathrm{DIV}_{k}=$ weather-dependent DIV for day $k$.

Calculation of DIV in the field was performed using hourly data from automatic weather stations. Hourly data were preferred because the day- and night-course of temperature and RH behave conversely and, therefore, daily averages may be a source of inaccuracy (26). Thus, DIV was computed as the average of 24 values resulting from the product of factors quantifying the effect of temperature and moisture:

$$
\mathrm{DIV}_{k}=1 / 24 \sum_{i=1}^{24} T_{k, i} \times M_{k, i}
$$

where $T_{k, i}=$ temperature index in the $i$ th hour on the $k$ th day and $M_{k, i}=$ moisture index in the $i$ th hour on the $k$ th day.

The effects of temperature and moisture were quantified after the generation of specific index values. The values were based on published data obtained by artificial inoculation of sugar beet plants under laboratory conditions in growth cabinets (26). The effect of temperature was quantified by the latent period (LP), which is defined here as including the entire period from inoculation, germination of conidia, infection, to symptom appearance and production of conidia. LP includes the entire disease cycle and, therefore, was considered most suitable to generate a temperature index $\left(T_{k, i}\right)$, which was expressed as a proportion of $\mathrm{LP}_{x, i}$ and $\mathrm{LP}_{\text {opt }}$ :

$$
T_{k, i}=\mathrm{LP}_{\mathrm{opt}} / \mathrm{LP}_{x, i}
$$

where $\mathrm{LP}_{\mathrm{opt}}=$ latent period at optimum temperature $\left(20\right.$ to $\left.25^{\circ} \mathrm{C}\right)$ and $\mathrm{LP}_{x, i}=$ latent period at temperature $x_{i}\left({ }^{\circ} \mathrm{C}\right)$ at hour $i$, calculated as

$$
\mathrm{LP}_{x, i}=7+26 \times \exp \left[0.35 \times\left(x_{i}-10\right)\right]
$$

The moisture index included information about the variables precipitation and RH. Previous experiments in growth cabinets established that leaf wetness or RH $>95 \%$ was required for infection (26). Under field conditions, on the other hand, leaf wetness was present with $75 \%$ frequency if $\mathrm{RH}$ was $>90 \%$ (25). Therefore, the moisture index $\left(\mathbf{M}_{k, i}\right)$ for hour $i$ on day $k$ was calculated as

$$
\begin{aligned}
& M_{k, i}=1 \text { if } \mathrm{RH}>90 \% \text { or precipitation } \geq 0.1 \mathrm{~mm} \text { or } \\
& M_{k, i}=0 \text { otherwise }
\end{aligned}
$$

Because, in nature, relationships are generally not dichotomous, we also derived an alternative expression for the moisture index. Related to the occurrence of leaf wetness in dependence of $\mathrm{RH}$ in the field, the relationship is described by a sigmoidal function (25). Arbitrarily, the index here was set to zero for $\mathrm{RH}$ 
$<70 \%$. This alternative expression of the moisture index was calculated as:

$$
M_{k, i}=1 /\left(1+\exp \left[\left(88-\mathrm{y}_{i}\right) / 2.5\right]\right) \text { where } y_{i}=\mathrm{RH}(\%) \text { during hour } i
$$

Overall, $T_{k, i}$ and $M_{k, i}$ summarize the quantitative influence of temperature and moisture on fungal growth as daily values in the range of 0 (no fungal growth) to 1 (optimal growth).

Weather data. Electronic weather stations (Adolf Thies $\mathrm{GmbH}$ \& Co. KG, Göttingen, Germany) were placed directly at the trial locations, comprising equipment for recording precipitation, temperature, and RH (both within the crop and $2 \mathrm{~m}$ aboveground). Each station consisted of two "Häckel" leaf wetness sensors, where an average was calculated based on measurements by a sensor located within the canopy and a second one outside of the canopy. These leaf wetness sensors consisted of wires that were harp-like in shape and attached to beet leaves by alternating two wires above and below the leaf. Measurements were taken at individual sensors at 15 -s intervals and were summarized for hourly periods.

At some sites, electronic weather stations from the Bavarian agrometeorological recording network were used. These stations were up to $15 \mathrm{~km}$ away from the trial locations. The station data loggers (Lambrecht, Göttingen, Germany) stored 10-min averages for calculating hourly or daily averages. Station equipment included sensors for temperature ( 0.2 and $2.0 \mathrm{~m}$ aboveground), $\mathrm{RH}$ ( $2.0 \mathrm{~m}$ aboveground), leaf wetness (1.0 $\mathrm{m}$ aboveground), and precipitation. All DIVs were calculated using data from sensors placed $2 \mathrm{~m}$ aboveground.

Data analysis. Data sets were tested for normal distribution (Kolmogorov-Smirnov test). If the calculated $P$ value was $>0.05$, normal distribution of the data was assumed. Then, c-DIV values from the 69 field trials were summarized by calculating minimum and maximum values and standard deviations of individual variables. In addition, one-way analyses of variance (ANOVA) were carried out to investigate the effects of the two different moisture indices $\left(M_{k, i}\right.$, equations $4 \mathrm{a}$ and $\left.4 \mathrm{~b}\right)$ on c-DIV. Variability of epidemic onset and c-DIV were indicated using box-whisker-graphs where each point represents the result of one field trial from one year, site, and cultivar. The box shows the range between the 25 th and 75 th percentiles, the horizontal line indicates the median value, and the whiskers extend from the edge of the box to the 5th and 95th percentiles. Confidence intervals for the medians are provided by notches surrounding the medians. If the notches about the two medians do not overlap, the medians are significantly different at an interval of $\pm 95 \%$ (8). Data analysis was con-

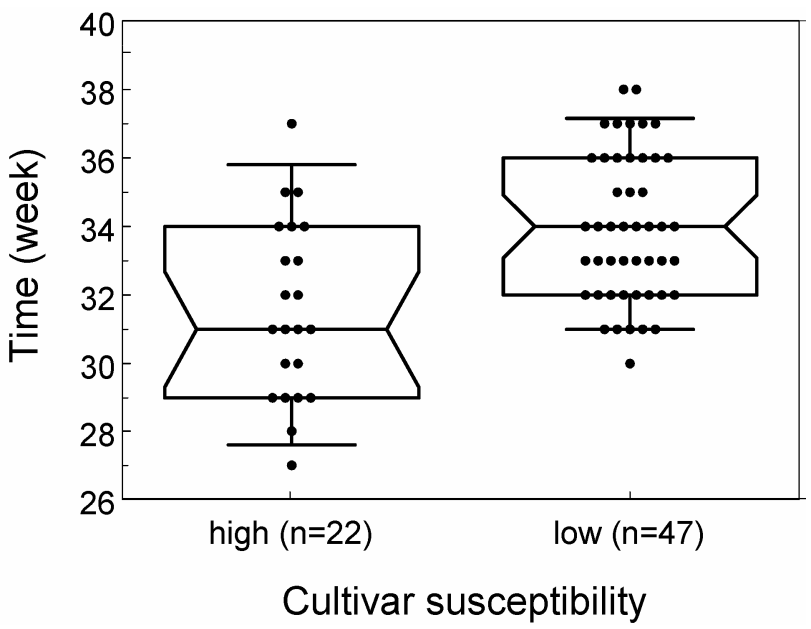

Fig. 1. Effect of sugar beet cultivar susceptibility on the variation of epidemic onset time of Cercospora leaf spot in 69 field trials in Germany. Epidemic onset was defined as the time when a disease incidence of $50 \%$ was reached. ducted using the programs "MedCalc" (MedCalc Software, Mariakerke, Belgium) and "SlideWrite Plus" (Advanced Graphics Software, Inc. Encinitas, CA).

\section{RESULTS}

Empirical analysis of epidemic onset. Variation of epidemic onset was normally distributed across the 69 data sets (Kolmogorov-Smirnov test for normal distribution: low susceptible cultivars, $P=0.34$; highly susceptible cultivars, $P=0.51$ ). From an empirical view, the epidemic onset occurred within calendar weeks 27 and 38 (i.e., in the period from the beginning of July until mid-September) (Fig. 1) and was influenced by cultivar resistance. In cultivars with low susceptibility, epidemic onset did not appear before calendar week 30 . The influence of cultivar susceptibility on epidemic onset also was evident from the medians, which were calendar week 31 for highly susceptible cultivars and 34 in case of lower susceptibility. The notches about the two medians do not overlap; therefore, the medians are significantly different at the $95 \%$ confidence level.

When comparing years, significant differences among the median dates of epidemic onset were found (Fig. 2). The median ranged from approximately week 28 to 36 . For instance, in 1993, the epidemic began relatively early in July. The epidemics of 1994, 1995, and 1998 began relatively later; whereas, in 1996 and 1997, they were delayed until later in the growing season. For any given year, the epidemic onset varied within a period of 5 to 8 weeks.

Although the total variation was reduced when considering cultivar resistance and year effects (Figs. 1 and 2), there remained significant differences in the times of epidemic onset, which partially may be due to different weather conditions. Thus, the question remained how weather conditions of different years and sugar beet-growing regions affect epidemic onset variation.

Effect of weather expressed as c-DIV. The analysis included the two different versions of the moisture index as described previously (equations $4 \mathrm{a}$ and $4 \mathrm{~b}$ ). In addition, the analysis was performed separately for cultivars with high and low susceptibility, where calculation of c-DIV compared fixed starting times with a flexible version of beginning cumulative addition from canopy closure onward. The latter indirectly considered the influence of canopy closure on microclimate $(11,26)$.

All c-DIV values were normally distributed according to Kolmogorov-Smirnov tests $(P>0.05)$. Medians of c-DIV as well as minimum and maximum values or standard deviation did not indicate differences between moisture index calculations. There-

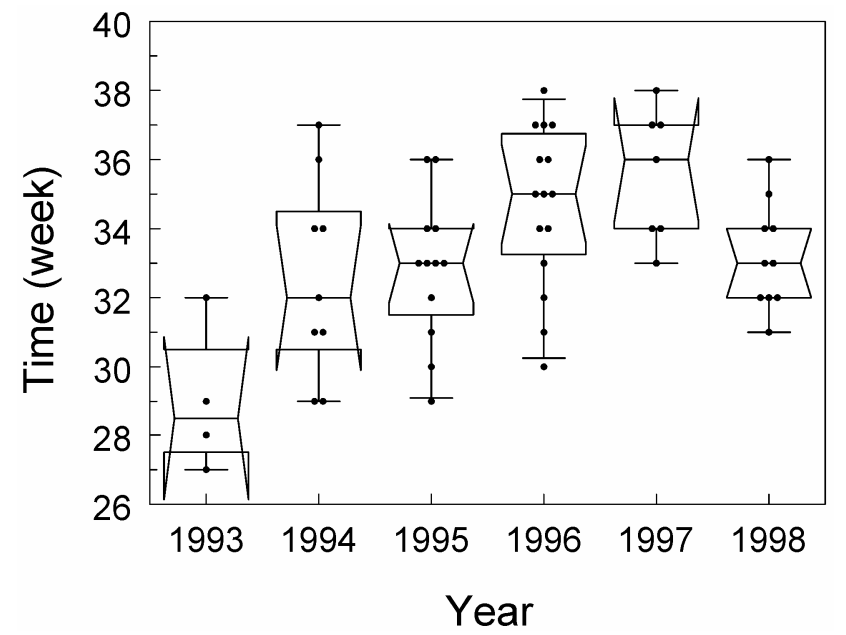

Fig. 2. Effect of year on the epidemic onset variation of Cercospora leaf spot in 69 sugar beet field trials in Germany. Epidemic onset was defined as the time when a disease incidence of $50 \%$ was reached. 
fore, the two definitions are equivalent (Table 2). On the other hand, cultivar resistance had a substantial impact on c-DIV. Moreover, differences between various starting times of c-DIV calculation (fixed dates versus the time of canopy closure) were pronounced (Table 2). Therefore, one-way ANOVA was performed within the starting times as subgroups. $F$ tests for the different definitions of moisture index $\left(M_{k, i}\right.$, equations $4 \mathrm{a}$ and $\left.4 \mathrm{~b}\right)$ were not significant at $P$ values varying between 0.10 and 0.25 for low susceptible cultivars and 0.32 and 0.51 for highly susceptible cultivars.

Concerning starting times for calculation of c-DIV, the smallest standard deviation was obtained by the flexible start of summation at canopy closure. However, the range between minimum and maximum values of c-DIV still was from 13.3 to 15.2 with standard deviations from 3.6 to 3.9. These values indicate a high variability of c-DIV. This suggests that explanation of different epidemic onset times is not sufficient to predict epidemic onset precisely.

Negative-prognosis. Based on the calculation of c-DIV starting at canopy closure, we evaluated the reciprocal approach of forecasting periods when there is a high probability that no infection will occur. The disease-free period was determined with the aid of a negative prognosis by identifying minimum values of c-DIV when epidemic onset occurred. The minimum value was c-DIV = 7 for highly susceptible cultivars; whereas, in cultivars of lower susceptibility, epidemic onset did not occur before c-DIV $=12$ (Fig. 3).

An example of the practical use of the negative prognosis based on minimum c-DIV values is illustrated in Figure 4. Based on the weather conditions (Fig. 4A), the daily infection values beginning with canopy closure were calculated (Fig. 4B). The point of time when epidemic onset cannot be excluded any longer was based on c-DIV values of 7 and 12 for low and highly susceptible cultivars, respectively (Fig. 4C). This was reached on 12 July for susceptible cultivars and 27 July for less susceptible cultivars. Monitoring of the crop then was to begin in order to determine actual epidemic onset.

\section{DISCUSSION}

This article focused on the attempt to explain different epidemic onset times of Cercospora leaf spot in order to select the most suitable disease prediction concept. Indispensable for this purpose were case studies of disease progress in the field over several years with variation of location, weather, host resistance, and other crop production factors. As a consequence, from the different combinations, a broad variation in the epidemic process resulted. This was the target of explanation. Based on our empirical approach, a part of the variation can be explained simply by the varying times of canopy closure $(28,30)$. Here, crop microclimate dynamics are a decisive influence variable. Another important part of variability is due to differing levels of cultivar resistance. The consideration and the uncomplicated way of including these factors are novel aspects and could be advantageous compared with other models. Despite these considerations, a precise forecast of epidemic onset was not possible due to the poor explanation of epidemic onset variation. There remains, as a consequence, only the possibility of applying a negative prognosis (i.e., determining minimum criteria as thresholds for disease outbreaks through calculation of periods that will remain free of disease with high probability). After thresholds for epidemic onset have been reached, an increasing risk of epidemic onset necessitates field observations (i.e., monitoring) to establish the actual disease incidence. On the other hand, direct decisions for spraying action cannot be taken from the information provided by a negative prognosis.

The negative prognosis model developed here will form part of the holistic plant protection system "sugar beet IPM model" $(28,30)$. This quaternary concept involves four elements of integrated crop protection: (i) negative prognosis to predict the likely disease-free period, (ii) subsequent monitoring of disease and determination whether the spray threshold is exceeded, and (iii) use of the economic damage threshold for (iv) loss prediction. Spray-

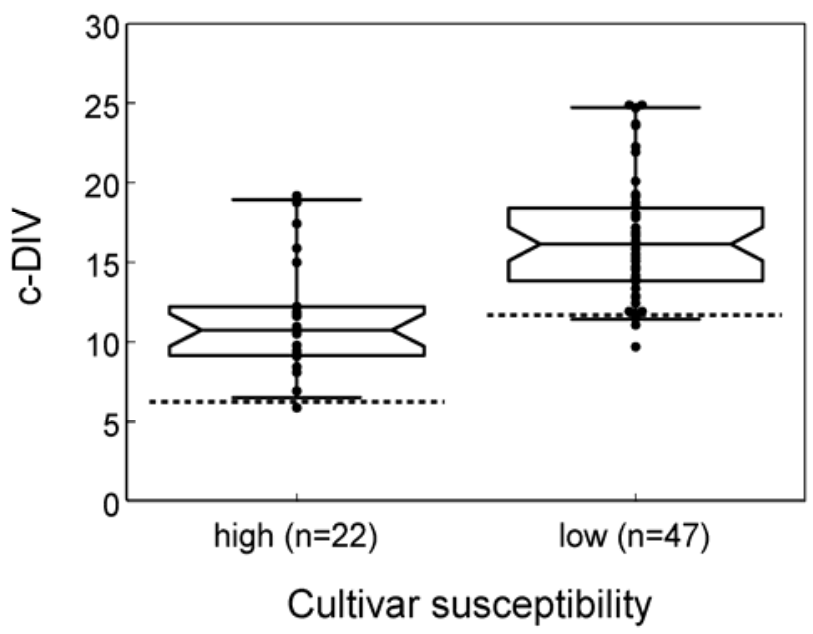

Fig. 3. Variation of the cumulative daily infection value (c-DIV) of Cercospora beticola calculated with weather data from canopy closure to epidemic onset based on 22 and 47 field trials with sugar beet cultivars of high and low susceptibility, respectively. c-DIV was calculated using equations 1 through $4 \mathrm{a}$ (described in text). Dotted lines indicate minimum c-DIV values for negativeprognosis (i.e., prediction of the likely disease-free period). Epidemic onset was defined as the time when a disease incidence of $50 \%$ was reached.

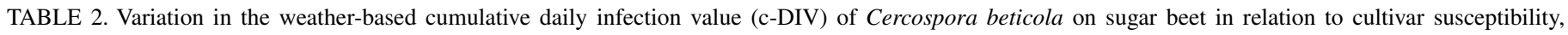
choice of the moisture index, and starting time of calculation ${ }^{\mathrm{a}}$

\begin{tabular}{|c|c|c|c|c|c|c|c|c|}
\hline & \multicolumn{4}{|c|}{ Moisture index I, starting time } & \multicolumn{4}{|c|}{ Moisture index II, starting time } \\
\hline & 1 May & 16 May & 1 June & Canopy closure & 1 May & 16 May & 1 June & Canopy closure \\
\hline \multicolumn{9}{|l|}{ Low susceptible cultivars } \\
\hline$P$ (Kol.-Smirnov test $)$ & 0.84 & 0.57 & 0.46 & 0.78 & 0.74 & 0.50 & 0.37 & 0.70 \\
\hline Median & 22.77 & 21.44 & 19.59 & 16.13 & 23.95 & 22.80 & 20.81 & 16.97 \\
\hline Minimum & 14.51 & 13.84 & 12.63 & 9.69 & 15.79 & 14.92 & 13.62 & 10.93 \\
\hline Maximum & 33.37 & 31.99 & 29.25 & 24.88 & 35.15 & 33.64 & 30.65 & 25.90 \\
\hline Standard deviation & 4.33 & 4.19 & 4.03 & 3.91 & 4.31 & 4.19 & 4.02 & 3.92 \\
\hline \multicolumn{9}{|c|}{ Highly susceptible cultivars } \\
\hline$P($ Kol.-Smirnov test $)$ & 0.40 & 0.46 & 0.43 & 0.31 & 0.52 & 0.44 & 0.42 & 0.60 \\
\hline Median & 16.65 & 15.58 & 13.66 & 10.75 & 18.09 & 16.67 & 14.59 & 11.56 \\
\hline Minimum & 10.07 & 9.25 & 7.75 & 5.88 & 10.94 & 9.96 & 8.29 & 6.31 \\
\hline Maximum & 27.09 & 25.71 & 22.97 & 19.18 & 28.62 & 27.11 & 24.12 & 19.79 \\
\hline Standard deviation & 4.37 & 4.20 & 4.07 & 3.64 & 4.38 & 4.22 & 4.10 & 3.65 \\
\hline
\end{tabular}

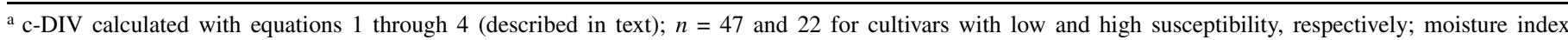
calculated with equations $4 \mathrm{a}$ and $4 \mathrm{~b}$. 
ing action is required if disease development is predicted to exceed the economic damage threshold before scheduled harvest time $(28,29)$.

Primary inoculum was not considered in the model due to very similar cropping conditions within the trial regions. In every case, sugar beet covered $\approx 15$ to $20 \%$ of the arable land and the crop rotation included a break of $\geq 2$ years with nonhost crops. A reliable and effective method to measure the field-specific inoculum was not available. As a consequence, an adequate consideration of field-specific inoculum level in the model was out of reach, perhaps a reason why precise field-specific prediction of the epidemic onset has failed. Moreover, the negative prognosis model requires adaptive validation in order to implement it in other growing areas as the basic cropping conditions may be different.

Prediction models for $C$. beticola have been developed previously for other sugar beet production areas. Battilani et al. (2) and Rossi and Battilani $(15,16)$ presented the model "Cercospora primary infections" (CERCOPRI) where weather-based infection probabilities are calculated based on addition of daily average values for temperature (only values $>5^{\circ} \mathrm{C}$ ) or $\mathrm{RH}$ (only values $>60 \%$ ). The totals were created from the beginning of the year and percentage probabilities of disease appearance were deduced primarily from the temperature totals in relation to higher and lower RH. A first symptom appearance was evident within a range of 1,000 to 1,700 degree-days (16). Hence, this model also may be interpreted as working like a negative prognosis, where the outbreak of disease cannot be excluded after exceeding a minimum degree-day value. The authors emphasize that the model is primarily for application in the area where it was developed. Results from greenhouse trials in combination with published data (22) form the basis of the Cercospora infection model developed by Shane et al. $(19,20)$. This model then was processed further by Windels et al. (24), especially regarding effective intro-
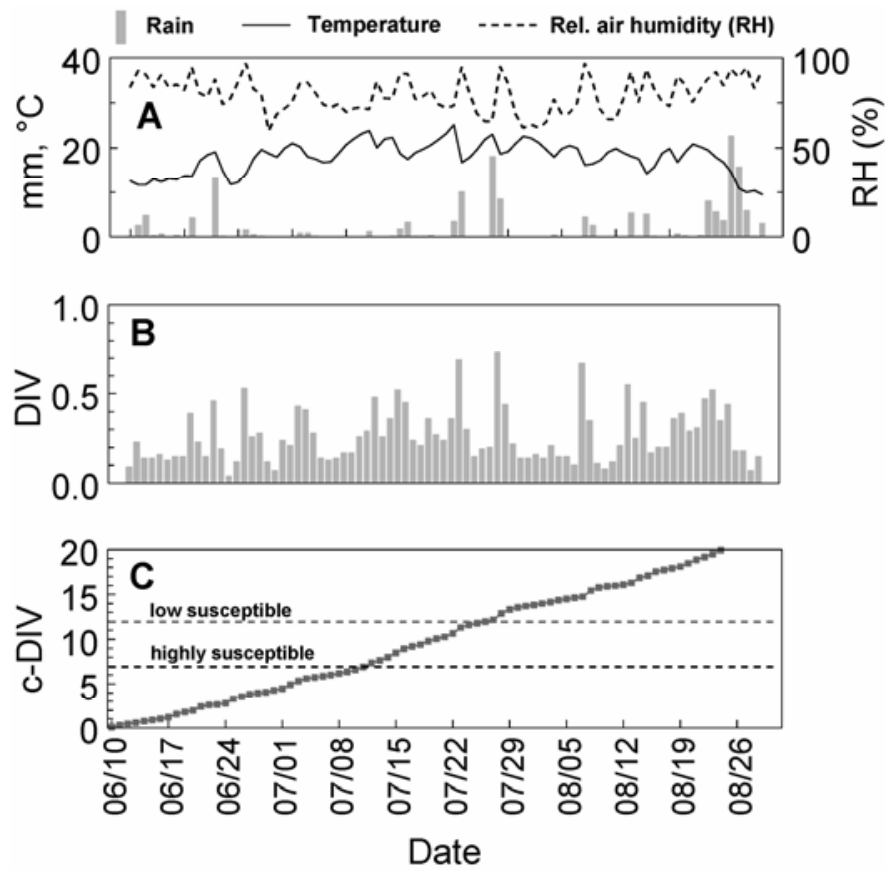

Fig. 4. Example of the practical use of negative-prognosis for Cercospora leaf spot of sugar beet based on a field trial in southern Germany (site Piering 1995). A, Daily values of mean air temperature, mean relative humidity, and rainfall; B, weather-based calculation of daily infection values (DIV); C, negative-prognosis based on cumulative DIV (c-DIV), where summation commences with canopy closure. Dotted lines indicate the thresholds when epidemic onset cannot be excluded any longer for highly and low susceptible cultivars. c-DIV was calculated using equations 1 through $4 \mathrm{a}$ (described in text). Epidemic onset was defined as the time when a disease incidence of $50 \%$ was reached. duction into practice. DIVs were derived from temperature and RH. DIVs ranged between 0 and 7 and were calculated on the basis of the number of hours per day with $\mathrm{RH}>90 \%$ and the average temperature during these hours. For Cercospora leaf spot prediction, two successive days were taken together in each case. If the DIV sum was $<6$, infection probability was low, a sum of 6 represented marginal, and sums from 7 to 14 signified favorable conditions. The authors indicate that the DIVs sometimes did not agree with the disease incidence determined in the field and suggested adaptations as necessary. In principle, this model also works like a negative prognosis because monitoring of the crop is recommended when a period with high infection probability has passed.

In summary, it can be concluded that, for the host-parasite system of sugar beet and $C$. beticola in Germany, a precise prediction of epidemic onset time is difficult and is prone to high variability. In the field, the individual factors of site, weather, crop development, and management act together in a complex way and their influences can be assessed only as approximations through mathematical formulae. After testing the possibilities of a prediction, so far only the form of the negative prognosis remains as a way of narrowing the relevant time span of epidemic onset. To avoid errors in plant protection, actual monitoring of crops in the field remains critical.

\section{ACKNOWLEDGMENTS}

We thank the Bavarian State Ministry for Agriculture and Nutrition, the Bavarian State Advisory Service, and to the Curatorium for Development of Sugar Beet Growing (Ochsenfurt) for financial support; the sugar beet and breeding companies, as well as the chemical industry, for technical support and cooperation; and all individuals who helped in the development of the model.

\section{LITERATURE CITED}

1. Anonymous. 2001. Beschreibende Sortenliste 2001. Landbuch Verlagsgesellschaft, Hannover, Germany.

2. Battilani, P., Racca, P., and Rossi, V. 1993. Sensitivity of a simulation model for Cercospora leaf spot on sugarbeet to meteorological data. SPRep. Danish Inst. Plant Soil Sci. 7:225-233.

3. Bleiholder, H., and Weltzien, H. C. 1972. Beiträge zur Epidemiologie von Cercospora beticola an der Zuckerrübe. 3. Geopathologische Untersuchungen. Phytopathol. Z. 73:93-114.

4. Bleiholder, H., and Weltzien, H. C. 1972. Beiträge zur Epidemiologie von Cercospora beticola Sacc. an Zuckerrübe. II. Die Konidienbildung in Abhängigkeit von den Umweltbedingungen, Temperatur, relative Luftfeuchtigkeit und Licht. Phytopathol. Z. 73:46-68.

5. Canova, A. 1959. Ricerche su la biologia e la epidemiologia della Cercospora beticola Sacc II. Ann. Sper. Agrar. 13:157-204.

6. Cooke, D. A., and Scott, R. K. 1993. The Sugar Beet Crop-Science into Practice. Chapman \& Hall, London.

7. Hoffmann, G. M., and Schmutterer, H. 1999. Parasitäre Krankheiten und Schädlinge an landwirtschaftlichen Kulturpflanzen. Eugen Ulmer, Stuttgart, Germany.

8. McGill, R., Tukey, J. W., and Larsen, W. A. 1978. Variation of box plots. Am. Stat. 32:12-16.

9. McKay, M. B., and Pool, V. W. 1918. Field studies of Cercospora beticola. Phytopathology 8:119-136.

10. Meier, U., Bachmann, E., Buhtz, H., Hack, H., Klose, R., Märländer, B., and Weber, E. 1993. Phenological growth stages of beta beets (Beta vulgaris L. spp.). Nachrichtenbl. Dtsch. Pflanzenschutzdienstes 45:37-41.

11. Mischke, W. 1960. Untersuchungen über den Einfluß des Bestandesklimas auf die Entwickung der Rüben-Blattfleckenkrankheit (Cercospora beticola Sacc.) im Hinblick auf die Einrichtung eines Warndienstes. Bayer. Landwirtsch. Jahrb. 37:197-227.

12. Pool, V. W., and McKay, M. B. 1916. Climatic conditions as related to Cercospora beticola. J. Agric. Res. 6:21-60.

13. Rossi, V. 1995. Effect of host resistance in decreasing infection rate of Cercospora leaf spot epidemics on sugarbeet. Phytopathol. Mediterr. 34:149-156.

14. Rossi, V., and Battilani, P. 1986. Impiego di variabili climatiche nella previsione delle infezione primarie di Cercospora beticola Sacc. Inf. Fitopathol. 36:29-38. 
15. Rossi, V., and Battilani, P. 1990. Dinamica delle epidemie di Cercospora beticola Sacc. su Barbabietola da zucchero. III. Ruolo della suscettibilita varietale. Phytopathol. Mediterr. 29:114-119.

16. Rossi, V., and Battilani, P. 1991. CERCOPRI: A Forecasting model for primary infections of Cercospora leaf spot of sugar beet. EPPO Bull. 21:527-531.

17. Rossi, V., Battilani, P., and Manici, L. 1988. Valutatione delle perdite produttive causate da Cercospora beticola Sacc. su barbietola da zucchero (Beta vulgaris L.). I. Epidemie di bassa intensitá. Riv. Agron. 22:105-111.

18. Schmidt, E. W. 1928. Untersuchungen über die Cercospora-Blattfleckenkrankheit der Zuckerrübe. Z. Parasitenkd. 1:100-137.

19. Shane, W. W., and Teng, P. S. 1983. Cercospora beticola infection prediction model. Sugar Beet Res. Ext. Rep. 23:174-179.

20. Shane, W. W., and Teng, P. S. 1985. Evaluation and implementation of the Cercospora leafspot prediction model. Sugar Beet Res. Ext. Rep. 15:129138.

21. Verreet, J. A., Wolf, P. F. J., and Weis, F. J. 1996. Bekämpfungsschwellen als Grundlage für eine integrierte Bekämpfung von Cercospora beticola-Das IPS-Modell Zuckerrübe. Pages 55-69 in: Proc. 59th IIRB Congress, Brussels.

22. Wallin, J. R., and Loonan, D. V. 1971. Effects of leaf wetness duration and air temperature in Cercospora beticola infection of sugarbeet. Phytopathology 61:546-549.

23. Weis, F. J. 1998. Entwicklung eines Integrierten Pflanzenschutzsystems zur schwellenorientierten Bekämpfung von Cercospora beticola in der Zuckerrübenkultur-IPS-Modell-Zuckerrübe. Agrimedia, Agribusiness \& Food, Bergen/Dumme, Germany.

24. Windels, C. E., Lamey, H. A., Hilde, D., Widner, J., and Knudson, T. 1998. A Cercospora leaf spot model for sugar beet. Plant Dis. 82:716-726.
25. Wolf, P. F. J. 2002. Über die Integration von Bekämpfungsmaßnahmen gegen pilzliche Blattkrankheiten der Zuckerrübe-IPS-Modell Zuckerrübe. Shaker Verlag, Aachen, Germany.

26. Wolf, P. F. J., Heindl, M., and Verreet, J. A. 2001. Zum Einfluß des Bestandesklimas auf die Prädisposition der Zuckerrübe gegenüber Infektionen von Cercospora beticola (Sacc.). Z. Pflanzenkrankh. Pflanzenschutz 108:578-592.

27. Wolf, P. F. J., Kraft, R., and Verreet, J. A. 1998. Schadrelevanz von Cercospora beticola (Sacc.) in Zuckerrüben als Grundlage einer Verlustprognose. Z. Pflanzenkrankh. Pflanzenschutz 105:462-474.

28. Wolf, P. F. J., and Verreet, J. A. 2002. Development and implementation of an integrated pest management system in Germany for the control of fungal leaf diseases in sugar beet: The IPM sugar beet model. Plant Dis. 86:336-344.

29. Wolf, P. F. J., and Verreet, J. A. 2003. Innovative combination of IPM(Integrated Pest Management) tools-The IPM Sugar Beet Model. Comm. Appl. Biol. Sci. Ghent Univ. 68:491-498.

30. Wolf, P. F. J., Verreet, J. A., Maier, H., and Köhler, R. 2000. Pages 103121 in: An Integrated Pest Management Model (IPM Sugar Beet Model) for Threshold-Oriented Control of Cercospora beticola on Sugar Beet, Developed Under Conditions in Southern Germany. International Institute for Beet Research, Brussels.

31. Wolf, P. F. J., Weis, F. J., and Verreet, J. A. 1995. Influence of different cropping systems and threshold values on the epidemiological behaviour of Cercospora beticola in sugar beet. Med. Fac. Landbowwet. Univ. Gent. 60/2b:431-438.

32. Wolf, P. F. J., Weis, F. J., and Verreet, J. A. 2001. Bekämpfungsschwellen als Indikatoren des Fungizideinsatzes zur Kontrolle des Blattbefalls von Cercospora beticola (Sacc.) in Zuckerrüben. Z. Pflanzenkrankh. Pflanzenschutz 108:244-257. 